\title{
ARTICLE \\ TU-DAMD employment for molecular characterization of Salvia judaica and Salvia palaestina species
}

\author{
Basel Saleh \\ Department of Molecular Biology and Biotechnology, Atomic Energy Commission of Syria, Damascus, Syria.
}

\begin{abstract}
Genetic diversity in perennial Salvia judaica Boiss (Judean sage) and Salvia palaestina Benth (Palestinian sage) species using touch-up directed amplification of minisatellite region DNA (TU-DAMD) has been performed in two separated sets; in the first set (set A) the initial annealing temperature was increased from $50^{\circ} \mathrm{C}$ to $55^{\circ} \mathrm{C}$, whereas, in the second one (set B), it increased from $55^{\circ} \mathrm{C}$ to $60^{\circ} \mathrm{C}$ by $0.5^{\circ} \mathrm{C} /$ cycle during the first 10 PCR amplification cycles. Fifteen DAMD primers have been tested for each set. Set (A) produced $89.39 \%$ polymorphism level (P\%) with polymorphic information content (PIC) average of 0.33 and marker index (MI) average of 3.96. Whereas, in set (B) these values were recorded to be $94.02 \%, 0.34$ and 3.98 for P\%, PIC and MI, respectively. Data showed that the two mentioned sets successfully highlighted high polymorphism level between the two studied Salvia sp. This work studies genetic diversity of S. judaica and S. palaestina species using TU-DAMD test as a novel molecular marker.
\end{abstract}

Acta Biol Szeged 65(1):11-16 (2021)

\author{
KEY WORDS \\ genetic diversity \\ Salvia judaica \\ Salvia palaestina \\ TU-DAMD \\ ARTICLE INFORMATION \\ Submitted \\ 02 February 2021. \\ Accepted \\ 22 February 2021 \\ *Corresponding author \\ E-mail: ascientific3@aec.org.sy
}

\section{Introduction}

Salvia genus belongs to Lamiaceae family, includes approximately 1000 species, and was considered as one of the largest plant genera (Walker et al. 2004). This genus commonly known as sage and it is considered as the largest genus within the family (Hu et al. 2018). According to Mouterde (1983), 28 Salvia species were grown along the Syrian coastline at different sea altitudes up to $900 \mathrm{~m}$.

Salvia judaica Boiss (Judean sage) is a perennial plant native to Mediterranean woodlands and shrublands (https://web.archive.org) and distributed in Turkey, Syria, Lebanon, and Palestine (Mouterde 1983). Whereas, Salvia palaestina Benth (Palestinian sage) is a perennial plant native to Palestine, Turkey, Syria, Iraq, Iran and the Sinai Peninsula and north-eastern Egypt (Loutfy 2002; Betsy 2003). It grows at wide range of habitats from 300 to 1220 m altitude.

Molecular markers have been widely and successfully used in plants genetic studies at genotypes, species and genera levels. Of which, directed amplification of minisatellite region DNA (DAMD) marker has been successfully employed in studies genetic variability of many plant species (Heath et al. 1993; Saleh 2019a).

More recently, Saleh (2019b) reported S. tomentosa species genetic diversity using touch-down directed amplification of minisatellite DNA (TD-DAMD) marker. The previous study reported various molecular markers that have been employed for genetic diversity of different Salvia species, e.g., random amplified polymorphic DNA (RAPD) marker in S. hispanica L. (Cahill 2004), inter simple sequence repeat (ISSR) marker in S. lachnostachys (Erbano et al. 2015), RAPD, amplified fragment length polymorphism (AFLP) (Wen et al. 2007), sequence-related amplified polymorphism (SRAP) and ISSR (Song et al. 2010) in S. miltiorrhiza Bge, nuclear ribosomal DNA and plastid DNA sequences in S. lutescens var. intermedia (Takano 2017), chloroplast simple sequence repeats (cpSSR's) in S. divinorum (Casselman 2016), chloroplast and nuclear ribosomal DNA sequences and allozyme polymorphisms in S. japonica (Sudarmono and Okada 2008) and directed amplification of minisatellite region DNA (DAMD) in Salvia sp. (Karaca et al. 2008).

DAMD maker has been developed for the first time in common bean landraces by Ince and Karaca (2011) to touch-down directed amplification of minisatellite DNA (TD-DAMD) marker. Then this maker has been used for molecular characterization of other plant species e.g. for Salvia species (Ince and Karaca 2012); Allium sp. (Deniz et al. 2013); carnation cultivars (Ince and Karaca 2015), commercial cotton (Gocer and Karaca 2016) and S. tomentosa (Saleh 2019b).

On the basis of TD-DAMD marker, an attempt has been carried out based on increasing annealing temperature by $0.5^{\circ} \mathrm{C} /$ cycle during the first 10 PCR amplification cycles in place to reducing it in TD-DAMD and thereby named as touch-up directed amplification of minisatellite DNA 
Table 1. Descriptive sites of collected studied samples in the current study.

\begin{tabular}{lllll}
\hline Species & Code & City province & Altitude $(\mathbf{m})$ & Annual rainfall $(\mathbf{m m})$ \\
\hline Salvia judiaca & SJ1 & Lattakia & 80 & 750 \\
Salvia judiaca & SJ2 & Lattakia & 600 & 750 \\
Salvia judiaca & SJ3 & Lattakia & 680 & 1250 \\
Salvia palaestina & SP4 & Damascus & 920 & 260 \\
Salvia palaestina & SP5 & Damascus & 950 & 260 \\
Salvia palaestina & SP6 & Damascus & 1200 & 150 \\
Ballota damascena & SD7 & Damascus & 970 & 260 \\
\hline
\end{tabular}

(TU-DAMD) in nouvelle test. Thereby, the current study highlights genetic diversity of S. judaica and S. palaestina species through TU-DAMD marker as a new assay for their molecular characterization.

\section{Materials and Methods}

\section{Plants materials}

Leaves samples (5-10 plants/genotype) were collected from Salvia judaica (rural Lattakia) (SJ) and Salvia palaestina (rural Damascus) (SP) species with Ballota damascena Boiss (Lamiaceae) (rural Damascus) (BD) as outside far reference, during blooming stage (Table 1). Samples were frozen in liquid nitrogen and kept at $-80^{\circ} \mathrm{C}$ until use.

\section{DNA isolation}

Total genomic DNA was extracted from frozen leaves samples (3 samples of $S$. judaica, 3 samples of $S$. palaestina and 1 sample of $B$. damascena) using CTAB (cetyltrimethylammonium bromide) method as described by Doyle and Doyle (1987).

\section{Touch-Up Directed Amplification of Minisatellite region DNA (TU-DAMD) test}

TU-DAMD test has been performed in two separated tests; in the first test (set A) the initial annealing temperature was increased from $50^{\circ} \mathrm{C}$ to $55^{\circ} \mathrm{C}$ by $0.5^{\circ} \mathrm{C} /$ cycle during the first 10 PCR amplification cycles. Whereas, in the second one (set B), it increased from $55^{\circ} \mathrm{C}$ to $60^{\circ} \mathrm{C}$ by $0.5^{\circ} \mathrm{C} /$ cycle during the first 10 PCR amplification cycles. Then, similar PCR amplification program was performed at annealing $\mathrm{Tm}$ of $55{ }^{\circ} \mathrm{C}$ for the both tests during the remaining 30 PCR amplification cycles as described by Seyedimoradi et al. (2012) for DAMD marker.

PCR products were separated on a $2 \%$ ethidium bromide-stained agarose (Bio-Rad) in $0.5 \times$ Tris-borate-EDTA (TBE) buffer, by electrophoresis at $85 \mathrm{~V}$ for $2.5 \mathrm{~h}$, and visualized with a UV transilluminator. PCR amplification products size was estimated with a $1 \mathrm{~kb}$ DNA ladder standard. Fifteen DAMD primers have been tested for each set to investigate genetic diversity in $S$. judaica and S. palaestina species (Table 2).

\section{TU-DAMD data analysis}

PCR products were photographed under UV, and each size class was scored as 0 or 1 for the absence or presence class, respectively. Unweighted pair group method using arithmetic averages (UPGMA) was constructed based on the estimated percent disagreement values (PDVs) using Statistica 6 (Statsoft 2003) program. Moreover, genetic similarity (GS) among examined samples was estimated according to Nei and Li (1979) index. Whereas, polymorphic information content (PIC) values were estimated for each tested primer according to the formula:

$$
\mathrm{PIC}=1-\sum(\mathrm{Pij})^{2}
$$

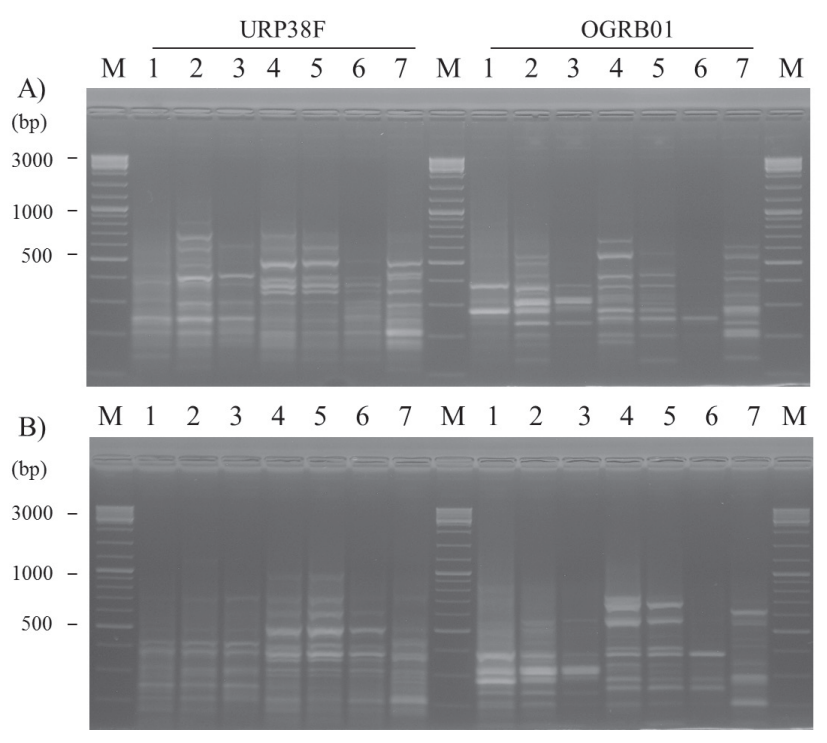

Figure 1. TU-DAMD polymorphism profile yielded by set (A): Tm increased from $50{ }^{\circ} \mathrm{C}$ to $55^{\circ} \mathrm{C}$ and set (B): Tm increased from $55^{\circ} \mathrm{C}$ to $60^{\circ} \mathrm{C}$ by $0.5^{\circ} \mathrm{C} /$ cycle during the first $10 \mathrm{PCR}$ amplification cycles using URP38F and OGRB01 DAMD primers for S. judaica (lines 1-3); $S$. palaestina (lines 4-6) and B. damascena (line 7). M: VC100bp Plus DNA Ladder (Vivantis) size standard. 
TU-DAMD characterization of Salvia species

Table 2. DAMD primers used in the current study.

\begin{tabular}{lll}
\hline Primer number & Primer name & Primer sequence 5'-3' \\
\hline 1 & URP1F & ATCCAAGGTCCGAGACAACC \\
2 & URP2R & CCCAGCAACTGATCGCACAC \\
3 & URP4R & AGGACTCGATAACAGGCTCC \\
4 & URP9F & ATGTGTGCGATCAGTTGCTG \\
5 & URP25F & GATGTGTTCTTGGAGCCTGT \\
6 & URP38F & AAGAGGCATTCTACCACCAC \\
7 & OGRB01 & AGGGCTGGAGGAGGGC \\
8 & FVIlex8C & CCTGTGTGTGTGAT \\
9 & FVIlex8 & ATGCACACACACAGG \\
10 & HBV5 & GGTGTAGAGAGGGGT \\
11 & 33.6 & GGAGGTGGGCA \\
12 & HVRC & CCTCCTCCCTCCT \\
13 & URP2F & GTGTGCGATCAGTTGCTGGG \\
14 & URP6R & GGCAAGCTGGTGGGAGGAC \\
15 & URP17R & AATGTGGGCAAGCTGGTGGT \\
\hline
\end{tabular}

Where Pij is the frequency of the $\mathrm{i}^{\text {th }}$ pattern revealed by the $j^{\text {th }}$ primer combination, summed across all patterns revealed by the primers (Botstein et al. 1980). Indeed, marker index (MI), a universal metric to represent the amount of information obtained per experiment for a given kind of marker was also estimated for each tested primer as described by Powell et al. (1996) according to the formula:

$$
\mathrm{MI}=\mathrm{PIC} \times \eta \beta
$$

Where PIC is the mean PIC value, $\eta$ the number of bands, and $\beta$ the proportion of polymorphism.

In the current study, statistical comparison based on Mantel test has been performed among TU- DAMD, A $(\operatorname{set} \mathrm{A}), \mathrm{B}(\operatorname{set} \mathrm{B})$ and $\mathrm{C}(\operatorname{set} \mathrm{A}+\mathrm{B})$ data.

\section{Results}

TU-DAMD test has been employed to investigate genetic diversity of $S$. judaica and $S$. palaestina species. Polymorphism pattern including set (A) and (B) as yielded by URP38F and OGRB01 DAMD primers was presented in Fig. 1. Data showed that for set (A), total bands number ranged between 8 (FVIIex8C)-18 (OGRB01) bands with a mean average of 13.20 bands/primer. Whereas, polymorphic bands number ranged between 8 (FVIIex8C) -18 (OGRB01) polymorphic bands with a mean average of 11.80 polymorphic bands/primer. Indeed, set (A) produced 198 bands of which 177 (89.39\%) were polymorphic. Whereas, PIC value ranged between 0.23 (HBV5) - 0.41 (URP25F) with a mean average of 0.33 (Table 3). As for
Table 3. Banding pattern of TU-DAMD amplified fragments scored.

\begin{tabular}{|c|c|c|c|c|c|}
\hline Set (A) & & & & & \\
\hline Primer name & TB & PB & $\mathrm{P} \%$ & PIC & $\mathrm{Ml}$ \\
\hline URP1F & 13 & 12 & 92.31 & 0.38 & 4.56 \\
\hline URP2R & 11 & 11 & 100.00 & 0.39 & 4.29 \\
\hline URP4R & 14 & 11 & 78.57 & 0.24 & 2.64 \\
\hline URP9F & 16 & 14 & 87.50 & 0.35 & 4.90 \\
\hline URP25F & 13 & 13 & 100.00 & 0.41 & 5.33 \\
\hline URP38F & 17 & 16 & 94.12 & 0.29 & 4.64 \\
\hline OGRB01 & 18 & 18 & 100.00 & 0.38 & 6.84 \\
\hline FVIIex8C & 8 & 8 & 100.00 & 0.39 & 3.12 \\
\hline FVIlex8 & 10 & 9 & 90.00 & 0.27 & 2.43 \\
\hline HBV5 & 15 & 11 & 73.33 & 0.23 & 2.53 \\
\hline 33.6 & 11 & 11 & 100.00 & 0.37 & 4.07 \\
\hline HVRc & 13 & 8 & 61.54 & 0.28 & 2.24 \\
\hline URP2F & 14 & 13 & 92.86 & 0.34 & 4.42 \\
\hline URP6R & 14 & 13 & 92.86 & 0.36 & 4.68 \\
\hline URP17R & 11 & 9 & 81.82 & 0.3 & 2.70 \\
\hline Total & 198 & 177 & & & \\
\hline Average & 13.20 & 11.80 & 89.66 & 0.33 & 3.96 \\
\hline \multicolumn{6}{|l|}{ Set (B) } \\
\hline Primer name & TB & PB & $\mathrm{P} \%$ & $\mathrm{PIC}$ & $\mathrm{Ml}$ \\
\hline URP1F & 14 & 14 & 100.00 & 0.34 & 4.76 \\
\hline URP2R & 8 & 8 & 100.00 & 0.33 & 2.64 \\
\hline URP4R & 16 & 14 & 87.50 & 0.34 & 4.76 \\
\hline URP9F & 14 & 14 & 100.00 & 0.32 & 4.48 \\
\hline URP25F & 8 & 8 & 100.00 & 0.4 & 3.20 \\
\hline URP38F & 18 & 14 & 77.78 & 0.31 & 4.34 \\
\hline OGRB01 & 18 & 18 & 100.00 & 0.39 & 7.02 \\
\hline FVIIex8C & 12 & 12 & 100.00 & 0.4 & 4.80 \\
\hline FVIlex8 & 7 & 6 & 85.71 & 0.23 & 1.38 \\
\hline HBV5 & 9 & 8 & 88.89 & 0.27 & 2.16 \\
\hline 33.6 & 16 & 16 & 100.00 & 0.34 & 5.44 \\
\hline HVRc & 11 & 10 & 90.91 & 0.32 & 3.20 \\
\hline URP2F & 8 & 7 & 87.50 & 0.35 & 2.45 \\
\hline URP6R & 15 & 14 & 93.33 & 0.37 & 5.18 \\
\hline URP17R & 10 & 10 & 100.00 & 0.39 & 3.90 \\
\hline Total & 184 & 173 & & & \\
\hline Average & 12.27 & 11.53 & 94.11 & 0.34 & 3.98 \\
\hline
\end{tabular}

TB: total bands; PB: polymorphic bands; P\%: polymorphic \%; PIC: polymorphic information content; Ml: marker index.

set (B), total bands number ranged between 7 (FVIIex8) - 18 (URP38F \& OGRB01) bands with a mean average of 12.27 bands/primer. Whereas, polymorphic bands number ranged between 6 (FVIIex8) - 18 (OGRB01) polymorphic bands with a mean average of 11.53 polymorphic bands/ primer. Indeed, set (B) produced 184 bands of which 173 (94.02\%) were polymorphic. Whereas, PIC value ranged between 0.23 (FVIIex8) - 0.40 (URP25F) with a mean 
A a)
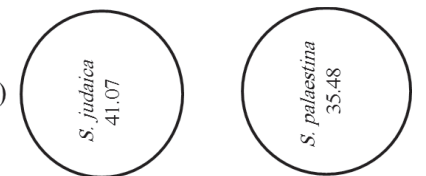

b)
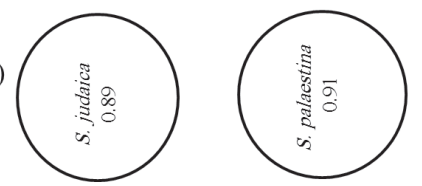

B

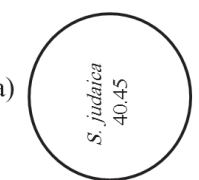

b)

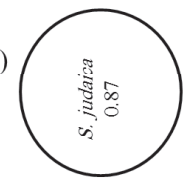

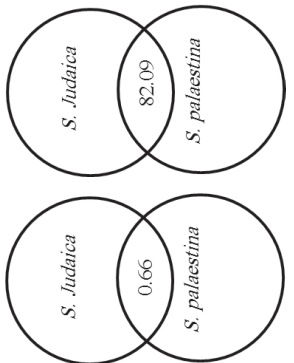
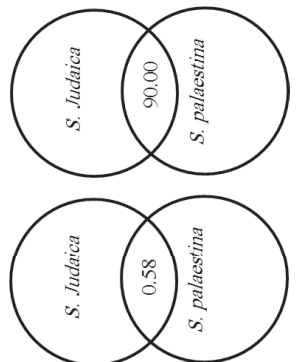

Figure 2. Polymorphism level (P\%) (a) and genetic similarity (GS) (b) values in S. judaica and S. palaestina species through TU-DAMD A (set A) and B (set B) data.

average of 0.34 (Table 3).

Genetic diversity was separately detected in the two studied Salvia sp. (Fig. 2). In this regards, for set (A), P\% was recorded to be $41.07,35.48$ and $82.09 \%$ with genetic similarity (GS) of $0.89,0.91$ and 0.66 for $S$. judaica, S. palaestina and $S$. judaica + S. palaestina together, respectively. As for set (B), these values were recorded to be 40.45 , 42.31 and $90.00 \%$ for P\% with GS of $0.87,0.89$ and 0.58 for S. judaica, S. palaestina and S. judaica + S. palaestina together, respectively.

UPGMA cluster analysis constructed (Fig. 3) based on PDV (Table 4), revealed that B. damascena was genetically so far from the two studied Salvia sp. Whereas, the two studied Salvia sp. were grouped into two main groups. The first group involved SJ samples; whereas, the second one involved SP samples (Fig. 3) for set (A), set (B) and set (A) + set (B) together.

Cluster analysis revealed that SJ1 and SJ3 and also SP4 and SP6 samples were the most closed samples by showing the lowest PDV value of 0.13 for set (A) (Table 4). As for set (B), SP5 and SP6 samples were the most closed samples by showing the lowest PDV value of 0.13 (Table 4).

Whereas, in set (A) and set (B) combination, SJ1 and SJ2 samples were the most closed samples by showing the lowest PDV value of 0.12 (Table 4).

Mantel test revealed a highly significant correlation among the possible combination. In this regards, very good fit $(\mathrm{r}=0.994)$ has been recorded between $\mathrm{A}+\mathrm{C}$ and $\mathrm{B}+\mathrm{C}$ data and also between $\mathrm{A}+\mathrm{B}$ data $(\mathrm{r}=0.977)$.

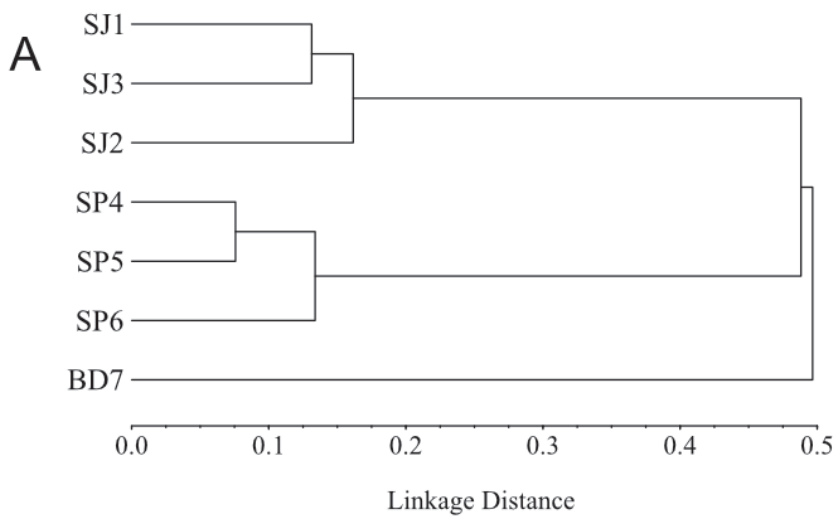

B
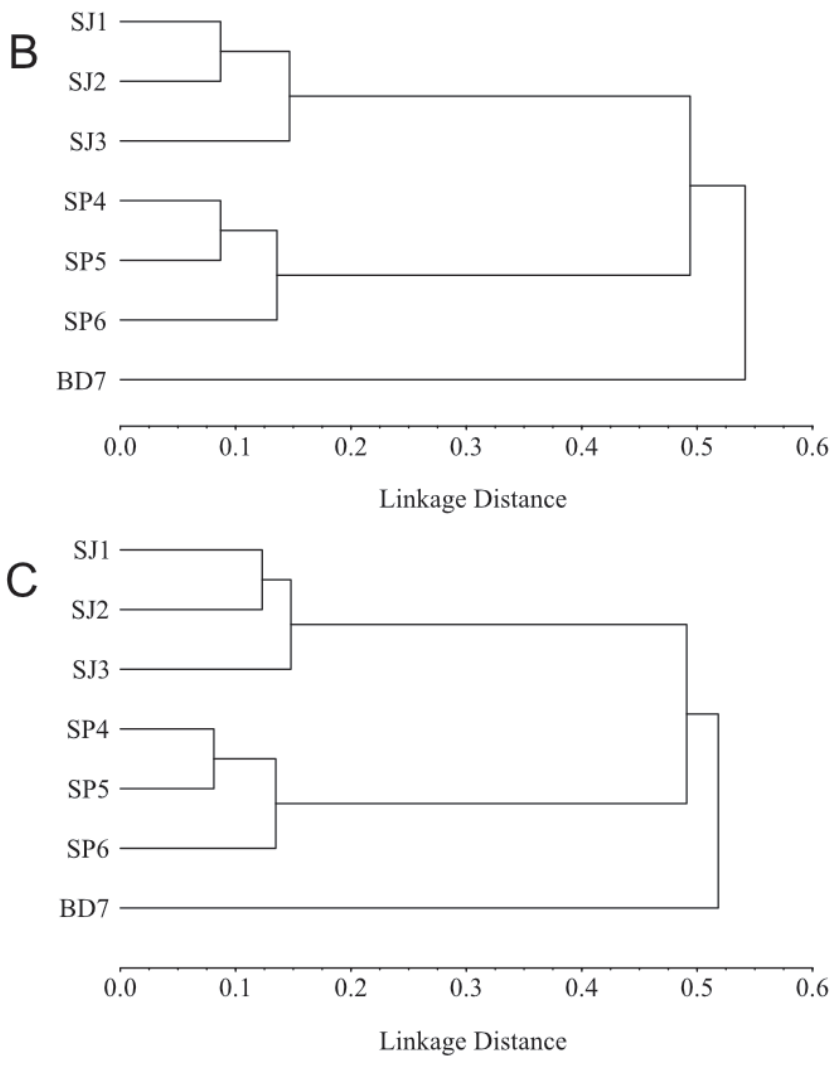

Figure 3. UPGMA Cluster analysis revealing relationships between $S$. judaica and S. palaestina through TU-DAMD A (set A), B (set B) and C (set $\mathrm{A}+\mathrm{B}$ ) data.

\section{Discussion}

Genetic diversity of $S$. judaica and $S$. palaestina species through TU-DAMD marker has been highlighted based on two (A) and (B) TU-DAMD sets.

The current study revealed that $\mathrm{P} \%$ for set (A), was recorded to be $41.07,35.48$ and $82.09 \%$; whereas, for set (B), these values were recorded to be $40.45,42.31$ and $90.00 \%$ for S. judaica, S. palaestina and S. judaica + S. 
Table 4. Percent disagreement values (PDV) yielded by TU-DAMD data based on UPGMA routine in statistical program.

\begin{tabular}{|c|c|c|c|c|c|c|c|}
\hline \multicolumn{8}{|l|}{ Set (A) } \\
\hline Genotype & SJ1* & SJ2 & SJ3 & SP4 & SP5 & SP6 & BD7 \\
\hline SJ1 & 0.00 & & & & & & \\
\hline SJ2 & 0.16 & 0.00 & & & & & \\
\hline SJ3 & 0.13 & 0.17 & 0.00 & & & & \\
\hline SP4 & 0.53 & 0.52 & 0.47 & 0.00 & & & \\
\hline SP5 & 0.51 & 0.48 & 0.44 & 0.08 & 0.00 & & \\
\hline SP6 & 0.49 & 0.53 & 0.42 & 0.13 & 0.14 & 0.00 & \\
\hline BD7 & 0.49 & 0.54 & 0.44 & 0.52 & 0.49 & 0.48 & 0.00 \\
\hline \multicolumn{8}{|l|}{ Set (B) } \\
\hline Genotype & SJ1 & SJ2 & SJ3 & SP4 & SP5 & SP6 & BD7 \\
\hline SJ1 & 0.00 & & & & & & \\
\hline SJ2 & 0.09 & 0.00 & & & & & \\
\hline SJ3 & 0.15 & 0.14 & 0.00 & & & & \\
\hline SP4 & 0.54 & 0.48 & 0.47 & 0.00 & & & \\
\hline SP5 & 0.52 & 0.47 & 0.47 & 0.09 & 0.00 & & \\
\hline SP6 & 0.54 & 0.48 & 0.48 & 0.14 & 0.13 & 0.00 & \\
\hline BD7 & 0.59 & 0.53 & 0.53 & 0.54 & 0.53 & 0.52 & 0.00 \\
\hline \multicolumn{8}{|l|}{ Set $(A)+(B)$} \\
\hline Genotype & SJ1 & SJ2 & SJ3 & SP4 & SP5 & SP6 & BD7 \\
\hline SJ1 & 0.00 & & & & & & \\
\hline SJ2 & 0.12 & 0.00 & & & & & \\
\hline SJ3 & 0.14 & 0.15 & 0.00 & & & & \\
\hline SP4 & 0.54 & 0.50 & 0.47 & 0.00 & & & \\
\hline SP5 & 0.51 & 0.47 & 0.46 & 0.08 & 0.00 & & \\
\hline SP6 & 0.52 & 0.51 & 0.45 & 0.13 & 0.14 & 0.00 & \\
\hline BD7 & 0.54 & 0.54 & 0.49 & 0.53 & 0.51 & 0.50 & 0.00 \\
\hline
\end{tabular}

Set A: The initial annealing temperature $(\mathrm{Tm})$ was increased from $50^{\circ} \mathrm{C}$ to $55^{\circ} \mathrm{C}$ and set $\mathrm{B}-\mathrm{Tm}$ increased from $55^{\circ} \mathrm{C}$ to $60^{\circ} \mathrm{C}$ by $0.5^{\circ} \mathrm{C} /$ cycle during the first 10 PCR amplification cycles.

*S. judaica (SJ1-SJ3), S. palaestina (SP4-SP6) and B. damascena (BD7).

palaestina together, respectively.

This observation could suggest low genetic diversity in S. judaica and S. palaestina. Our data were coherent with Safaei et al. (2016), who reported that P\% was recorded to be $38.46,47.25,57.14,49.45,42.86$ and $28.57 \%$ for $S$. hypoleuca, S. nemorosa, S. limbata, S. xanthocheila, S. spinosa and $S$. reuterana, respectively, using 10 ISSR primers. Similarly, Altindal (2019) reported P\% of $32.03 \%$ in $S$. officinalis using 16 ISSR primers. Similar observation has been also noted by Tonk et al. (2010) in other Lamiaceae family members, who reported that GS values ranged between $0.49-0.73$ indicated low genetic variability in Turkish oregano (Origanum onites L.) species using RAPD marker. Moreover, Gocer and Karaca (2016) reported 120 total bands, of which 42 (35\%) were polymorphic among 26 cotton samples using 10 DAMD primers.
However, high genetic diversity has been recorded in other Lamiaceae family members. In this regards; Swamy and Anuradha (2011) reported 96 total bands of which 80 (83.3\%) were polymorphic in patchouli cultivars (Pogostemon cablin Benth.) using RAPD marker. Moreover, Talebi et al. (2015) reported 240 total bands of which 198 (82.5\%) were polymorphic with a mean average PIC of 0.248 in Thymus daenensis subsp. daenensis using SRAP marker. Indeed, Tapeh et al. (2018) reported 198 total bands of which 184 (92.9\%) were polymorphic with a mean PIC average of 0.39 in Iranian Teucrium (Teucrium polium L.) populations using ISSR marker.

More recently, Saleh (2019b) reported 158 total bands of which 131 (82.911\%) were polymorphic with a mean PIC and MI values of 0.264 and 2.269, respectively, in $S$. tomentosa based on Td-DAMD marker.

Since the molecular marker efficacy depend on the produced polymorphism degree; the current study could suggest that the two sets similarly and successfully highlighted genetic diversity between the two studied Salvia spices by showing similar PIC and MI values of 0.33 and 3.96 and 0.34 and 3.98 between S. judaica and S. palaestina species for set (A) and set (B), respectively.

\section{Conclusion}

Genetic diversity in $S$. judaica and S. palaestina species has been highlighted based on two TU-DAMD (A) and (B) sets. This work revealed that the two employed sets gave similar highly genetic diversity between the two studied Salvia sp. Whereas, low genetic diversity within each species has been recorded using the two employed sets. Based on data presented herein, it worth noting to use and validate this novel assay for molecular characterization of other plant species.

\section{Acknowledgements}

I thank Dr. I. Othman (Director General of AECS) and Dr. N. Mirali (Head of Molecular Biology and Biotechnology Department in AECS) for their support, and the Plant Biotechnology group for technical assistance.

\section{References}

Altindal D (2019) Determination of genetic diversity of natural sage populations in Muğla region of Turkey. Int J Environ Sci Technol 16(2):1-6.

Betsy C (2003) The New Book of Salvias: Sages for Every Garden. Timber Press. 
Botstein D, White RL, Skolinck M, Davis RW (1980) Construction of a genetic linkage map in man using restriction fragment length polymorphisms. Am J Hum Gene 32:314-331.

Cahill JP (2004) Genetic diversity among varieties of Chia (Salvia hispanica L.). Gen Res Crop Evol 51(7):773-781.

Casselman I (2016) Genetics and phytochemistry of Salvia divinorum. PhD Thesis, Southern Cross University, Lismore, NSW.

Deniz I, Genc I, Ince AG, Aykurt C, Elmasulu S, Sümbül H, Sönmez S, Çitak S (2013) Taxonomic data supporting differences between Allium elmaliense and Allium cyrilli. Biologia 68(3):373-383.

Doyle JJ, Doyle JL (1987) A rapid DNA isolation procedure for small quantities of fresh leaf tissue. Phytochem Bull 19:11-15.

Erbano M, Schühli SG, dos Santos ÉP (2015) Genetic variability and population structure of Salvia lachnostachys: Implications for breeding and conservation programs. Int J Mol Sci 16:7839-7850.

Gocer EU, Karaca M (2016) Genetic characterization of some commercial cotton varieties using Td-DAMD-PCR markers. J Sci Engin Res 3(4):487-494.

Heath DD, Iwama GK, Devlin RH (1993) PCR primed with VNTR core sequence yields species specific patterns and hypervariable probes. Nucl Acid Res 21:5782-5785.

Hu G-X, Takano A, Drew BT, Liu E-D, Soltis DE, Soltis PS, Peng H, Xiang C-L (2018) Phylogeny and staminal evolution of Salvia (Lamiaceae, Nepetoideae) in East Asia. Ann Bot 122:649-668.

Ince AG, Karaca M (2011) Genetic variation in common bean landraces efficiently revealed by Td-DAMD-PCR markers. Plant Omics 4(4):220-227.

Ince AG, Karaca M (2012) Species-specific touch-down DAMD-PCR markers for Salvia species. J Med Plant Res 6(9):1590-1595.

Ince AG, Karaca M (2015) Td-DAMD-PCR assays for fingerprinting of commercial carnations. Turk J Biol 39:290298.

Loutfy B (2002) Flora of Egypt, Volume 3: VerbenaceaeCompositae. Al Hadara Pub.

Mouterde PSJ (1983) Nouvelle Flore du Liban et de la Syria. Part 3. pp.159-170.

Nei M, Li W (1979) Mathematical model for studying genetic variation in terms of restriction endonucleases. Proc Natl Acad Sci USA 76:5269-5273.

Powell W, Morgante M, Andre C, Hanafey M, Vogel J, Tingey S, Rafalski A (1996) The comparison of RFLP, RAPD, AFLP and SSR (microsatellite) markers for germplasm analysis. Mol Breed 2:225-238.
Safaei M, Sheidai M, Alijanpoor B, Noormohammadi Z (2016) Species delimitation and genetic diversity analysis in Salvia with the use of ISSR molecular markers. Acta Bot Croat 75(1):45-52.

Saleh B (2019a) Molecular characterization using directed amplification of minisatellite-region DNA (DAMD) marker in Ficus sycomorus L. (Moraceae). Open Agric J 13:74-81.

Saleh B (2019b) Genetic diversity of Salvia tomentosa Miller (Lamiaceae) species assessment using Td-DAMD molecular marker. Acta Biol Szeged 63(2):135-141.

Seyedimoradi H, Talebi R, Hassani D, Karami F (2012) Comparative genetic diversity analysis in Iranian local grapevine cultivars using ISSR and DAMD molecular markers. Environ Exp Biol 10:125-132.

Song Z, Li X, Wang H, Wang J (2010) Genetic diversity and population structure of Salvia miltiorrhiza Bge in China revealed by ISSR and SRAP. Genetica 138:241-249.

Statsoft Statistica (2003) (Data analysis software system), Version 6, Statsoft Inc., www.statsoft.com

Sudarmono S, Okada H (2008) Genetic differentiations among the populations of Salvia japonica (Lamiaceae) and its related species. HAYATI J Biosci 15(1):18-26.

Swamy KM, Anuradha (2011) Analysis of genetic variability in patchouli cultivars (Pogostemon cablin Benth.) by using RAPD markers. Res Biotechnol 2(6):64-71.

Takano A (2017) Taxonomic study on Japanese Salvia (Lamiaceae): Phylogenetic position of S. akiensis, and polyphyletic nature of $S$. lutescens var. intermedia. Phyto Keys 80:87-104.

Talebi M, Rahimmalek M, Norouzi M (2015) Genetic diversity of Thymus daenensis subsp. daenensis using SRAP markers. Biologia 70(4):453-459.

Tapeh RNG, Bernousi I, Moghadam AF, Mandoulakani BA (2018) Genetic diversity and structure of Iranian Teucrium (Teucrium polium L.) populations assessed by ISSR markers. J Agr Sci Tech 20:333-345.

Tonk FA, Yüce S, Bayram E, Giachino RRA, Sönmez Ç, Telci İ, Furan MA (2010) Chemical and genetic variability of selected Turkish oregano (Origanum onites L.) clones. Plant Syst Evol 288(3-4):157-165.

Walker JB, Sytsma KJ, Treutlein J, Wink M (2004) Salvia (Lamiacae) is not monophyletic: Implications for the systematics, radiation, and ecological specializations of Salvia and tribe Mentheae. Am J Bot 91:1115-1125.

Wen C, Wu Z, Tian W, Liu M, Zhou Q, Xie X (2007) AFLP analysis of genetic diversity of Salvia miltiorrhiza Bge. Acta Agric Bor-Sin 22(S2):122-125. 